\section{Direct Shoot Regeneration from Vaccinium pahalae (Ohelo) and $V$. myrtillus (Bilberry) Leaf Explants}

\author{
Rida A. Shibli ${ }^{1}$ and M.A.L. Smith ${ }^{2}$ \\ Department of Natural Resources and Environmental Sciences, 1021 Plant \\ Sciences Laboratory MC-634, University of Illinois, Urbana, IL 61801
}

Additional index words. acclimatization, micropropagation, organogenesis, rhizogenesis

\begin{abstract}
Ohelo (V.pahalae Skottsb.) and bilberry (V. myrtillus L.) shoots were regenerated via direct organogenesis from whole leaves and leaf sections and also from hypocotyl explants of bilberry. Explants preincubated for 1 to 2 weeks in darkness yielded $\approx 75 \%$ regeneration frequencies and the highest number of regenerating shoots/explant on TDZsupplemented media $(0.9$ to $2.7 \mu \mathrm{M})$. When $2 \mathrm{iP}$ or zeatin were substituted as the cytokinin source, frequencies of regeneration and shoot productivity were significantly lower. Explants held under constant illumination (no dark pretreatment) had significantly lower regeneration frequencies in all tested cytokinin-supplemented media. 2,4-D stimulated callus formation, but did not support regeneration from vegetative explants. Cells from callus and suspension cultures did not exhibit regeneration in any of the media that supported organogenesis from leaves. Regenerants were successfully micropropagated, although callus formation caused by zeatin and high $2 \mathrm{iP}$ levels interfered with shoot proliferation. Zeatin induced hyperhydricity in shoots from both species, but more severely in ohelo. Ex vitro rooting after treatment with $4.9 \mu_{\mathrm{M}} \mathrm{IBA}$ or $5.4 \mu_{\mathrm{M}} \mathrm{NAA}$ was $95 \%$ and $60 \%$ successful for bilberry and ohelo, respectively, and plants were readily acclimatized after an interval in a fog chamber. Bilberry microshoots also rooted in vitro in the absence of growth regulator treatment. Chemical names used: $1 \mathrm{H}$-indole-3-butanoic acid (IBA); $\boldsymbol{N}$-(3-methyl-2-butenyl)-1- $H$-purine-6-amine (2iP); 6-furfurylaminopurine (kinetin); 1-naphthaleneacetic acid (NAA); thidiazuron=1-phenyl-3-(1,2,3-thiadiazio-5-yl)urea (TDZ); 2,4-dichlorophenoxyacetic acid (2,4-D); 6-(4-hydroxy-3-methylbut-2-enylamino) purine (zeatin).
\end{abstract}

Two Vaccinium species, V. pahalae (common name ohelo) and $V$. myrtillus (common name bilberry), were recently selected as promising sources for the production of anthocyanin pigment and other bioactive phytochemicals in callus, suspension, and bioreactor-based cultures (Madhavi et al., 1995). Both species produce edible fruit and are considered "four-season" landscape specimen plants with attractive spring and fall foliage color, yellow twigs, and brightly colored berries that attract wildlife (personal communication, Dan Hartmann, Hartmann's Plantation, Grand Junction, Mich.). Fruit of bilberry, in particular, are well recognized for cardioprotective benefits (Colatuoni et al., 1991; Morazzoni and Bombardelli, 1996) Because of their unique properties as edible resources for nonnutritive health benefits and

Received for publication 9 Apr. 1996. Accepted for publication 21 July 1996. This work was supported in part by a grant from the Univ. of Illinois College of Agricultural, Consumer, and Environmental Sciences Value-Added Program. Original V. pahalae plants were obtained from the U.S. Dept. of Agriculture/Agricultural Research Service Clonal Germplasm Repository, Corvallis, Ore. The cost of publishing this paper was defrayed in part by the payment of page charges. Under postal regulations, this paper therefore must be hereby marked advertisement solely to indicate this fact.

${ }^{1}$ Assistant Professor of Plant Physiology.

${ }^{2}$ Professor of Plant Physiology. To whom reprint requests should be addressed. as sources for extraction of natural colorants, both cultivars have excellent potential as "functional food" crops, which are gaining an increasing hold in the global marketplace (Childs, 1995).

Direct regeneration from vegetative tissues facilitates genetic transformation with minimal alteration of the target plant genome (Mohamed et al., 1992), which is a useful strategy for research aimed at amplifying or modifying specific phytochemical yields. Organogenesis from leaf disks was reported in blueberry ( $V$. corymbosum L.) on media containing the cytokinins 2iP (Callow et al., 1989), zeatin riboside, or zeatin (Rowland and Ogden, 1992). Pretreatment of cranberry ( $V$. macrocarpon Ait.) stem sections with cytokinins made them competent to produce adventitious buds after particle bombardment (Serres et al., 1992).

Micropropagation, which allows scaledup clonal production of selected genotypes, has been accomplished for several Vaccinium species, including highbush (V. corymbosum L.) and lowbush ( $V$. angustifolium Ait.) blueberry (Finn et al., 1991; Isutsa et al., 1994; Reed and Esquivel, 1991), lingonberry ( $V$. vitis-idaea L.) (Hosier et al., 1985), and cranberry (V. macrocarpon Ait.) (Marcotrigiano and McGlew, 1991). The objectives of this study were to establish a system for direct regeneration of shoots, in vitro shoot multiplication, rooting, and ex vitro acclimatization of the two target genotypes.
Regeneration. Bilberry seed was extracted from dried fruit (Sheffield's Seed Co., New York), surface-disinfested, and germinated in a basal modified MS medium (Murashige and Skoog, 1962). In vitro cultures of ohelo were received from the National Clonal Germplasm Repository (Corvallis, Ore.). Uniform shoot cultures were established by subculturing microshoots ( 3.0 to $4.0 \mathrm{~mm}$ ) to modified MS medium containing $12.3 \mu \mathrm{M} 2 \mathrm{iP}$ (for bilberry) or woody plant medium (WPM) (Lloyd and McCown, 1980) supplemented with $18.2 \mu \mathrm{M}$ zeatin (for ohelo), on 7-week intervals. Bilberry was maintained at a photosynthetic photon flux (PPF) of $45 \mu \mathrm{mol} \cdot \mathrm{m}^{-2} \cdot \mathrm{s}^{-1}$ at $22 \pm 1^{\circ} \mathrm{C}$. Ohelo was maintained at a reduced irradiance level $\left(20 \mu \mathrm{mol} \cdot \mathrm{m}^{-2} \cdot \mathrm{s}^{-1}\right)$ because microplants exhibited slow growth and decline under higher light intensity.

Leaves (with petioles) excised from microshoots were placed on the surface of media containing one of the following treatments: $0.0,9.1,18.2$, or $27.2 \mu \mathrm{M} 2,4-\mathrm{D} ; 0.0$, $9.1,18.2$, or $27.4 \mu \mathrm{m}$ zeatin; $0.0,0.9,1.8$, or 2.7 $\mu_{\mathrm{M}} \mathrm{TDZ}$; or $0.0,19.7,39.4$, or $59.0 \mu \mathrm{M} 2 \mathrm{iP}$. For each replicate, a total of six leaves was placed (with the abaxial leaf surfaces in contact with the medium) on the surface of $40 \mathrm{~mL}$ medium in GA7 (Magenta Corp., Chicago) cubes. Growth regulator treatments were separated into one of three light regimes: immediate exposure to light or dark storage for 1 or 2 weeks before light exposure. Each plant growth regulator/light regime treatment consisted of 10 replications, and data on percent regeneration, number of regenerated shoots/explant, and incidence of callus formation were recorded after 4 weeks.

The same growth regulator treatments were applied to leaf halves cut longitudinally on the midrib, but all of these replications were held in dark storage for 1 week before light exposure. Hypocotyls from germinating bilberry seedlings were tested under the same growth regulator treatments and stored in the dark for 2 weeks before exposure to light. Leaf sections (interveinal regions) from both species and cotyledons from germinating bilberry seedlings were similarly tested over a reduced number of plant growth regulator treatments $(1.8 \mu \mathrm{M}$ TDZ ; $59.0 \mu \mathrm{M} 2 \mathrm{iP}$; or $27.4 \mu \mathrm{M}$ zeatin $)$ as described above, with 2 weeks storage in the darkness.

Callus was induced from leaves of both species and maintained with a subculture interval of 3 to 4 weeks on WPM containing 5.4 $\mu \mathrm{M}$ NAA, $0.5 \mu \mathrm{M} 2,4-\mathrm{D}$, and $2.3 \mu \mathrm{M}$ kinetin. Then it was tested (after two to three subculture intervals) under the same growth regulator treatments as described for whole-leaf regeneration for the species. Callus was either maintained on the same medium or transferred to growth regulator-free medium after 3 weeks to test the effects on organogenesis. In separate experiments, callus segments $(1.0 \mathrm{~g})$ were transferred to $125 \mathrm{~mL}$ suspension culture flasks containing $40 \mathrm{~mL}$ of each regeneration medium. As described for the whole-leaf regeneration experiments, 10 replications were tested 
for each unique treatment combination.

In vitro shoot proliferation. Uniform, regenerated microshoots ( 3.0 to $4.0 \mathrm{~mm}$ ) were subcultured to $40 \mathrm{~mL}$ MS (bilberry) or WPM (ohelo) medium containing $2 \mathrm{iP}(0.0,9.8,19.7$, or $29.5 \mu \mathrm{M})$ or zeatin $(0.0,9.1,18.2$, or 27.4 $\mu \mathrm{M})$. Each treatment consisted of 15 GA7 cubes (replications), and treatments were completely randomized. Data were collected on number of shoots, shoot height, and callus formation at 4 and 8 weeks. After 8 weeks, shoots were removed from culture vessels and blotted with tissue paper (Kimwipes EX-L; Kimberly-Clark, Canada) to remove agar and moisture. Fresh mass (FM) was determined and shoots were then dried to a constant mass at $70^{\circ} \mathrm{C}$ for dry mass (DM) determination. The experiment was repeated once.

\section{Rooting and acclimatization}

Microshoots were subcultured to $10 \mathrm{~mL}$ rooting medium in $15 \times 2.5$-cm culture tubes containing $0.0,9.8,19.7$, or $29.5 \mu \mathrm{M}$ of IBA or $0.0,10.7,21.5$, or $32.2 \mu \mathrm{M}$ NAA. Rooting treatments had 20 replications (individual culture tubes). Data were reported after 4 and 8 weeks for percent rooting and root count. The experiment was repeated once. In vitro rooted microshoots were transferred to acclimatization under continuous light (PPF $=40$ to 50 $\mu \mathrm{mol} \cdot \mathrm{m}^{-2} \cdot \mathrm{s}^{-1}$ ) in a fog chamber for 4 weeks at $27 \pm 1^{\circ} \mathrm{C}$. Relative humidity was maintained at $95 \%$ to $100 \%$ during the first 4 days with the aid of an ultrasonic humidifier, then decreased gradually over the remainder of the acclimatization period. Acclimatized microshoots were moved under an intermittent water mist ( $8 \mathrm{~s} \cdot 6$ $\left.\mathrm{min}^{-1}\right)$ in the greenhouse $\left(25 \pm 2{ }^{\circ} \mathrm{C}\right.$ day/18 \pm $2{ }^{\circ} \mathrm{C}$ night) for 2 weeks for further growth and development. Intermittent mist was operated just during daylight hours. Acclimatized shoots were next moved into a greenhouse and were maintained with routine overhead irrigation.

Other shoots were excised from in vitrogrown plants and either directly inserted into a soilless mixture ( 1 peat : 1 perlite) and held in the acclimatization fog chamber, or the basal ends of the microshoots were dipped for 2 to 3 $\mathrm{s}$ in a $4.92 \mu \mathrm{M}$ IBA or $5.37 \mu \mathrm{M}$ NAA solution before insertion. Ex vitro rooted cuttings were moved after acclimatization to the greenhouse (under intermittent mist) for 2 weeks as described above, then moved to a greenhouse. After 3 weeks, a general-purpose N24-P12K12 Peters soluble fertilizer (Grace Sierra) at $2.0 \mathrm{~g} \cdot \mathrm{L}^{-1}$ was added $(5 \mathrm{~mL} /$ plant $)$ to encourage the growth of the plants. Data were reported on survival percentage and performance of these plants under acclimatization.

Statistical analysis. All data were subjected to linear regression analysis by the general linear models procedure (SAS, 1985; SAS Inst., Cary, N.C.).

\section{Results and Discussion}

Regeneration. Shoots regenerated directly from the leaf tissue of ohelo and bilberry. Petioles, midribs, leaf margins, wounded and interveinal regions of the leaf were all sites for

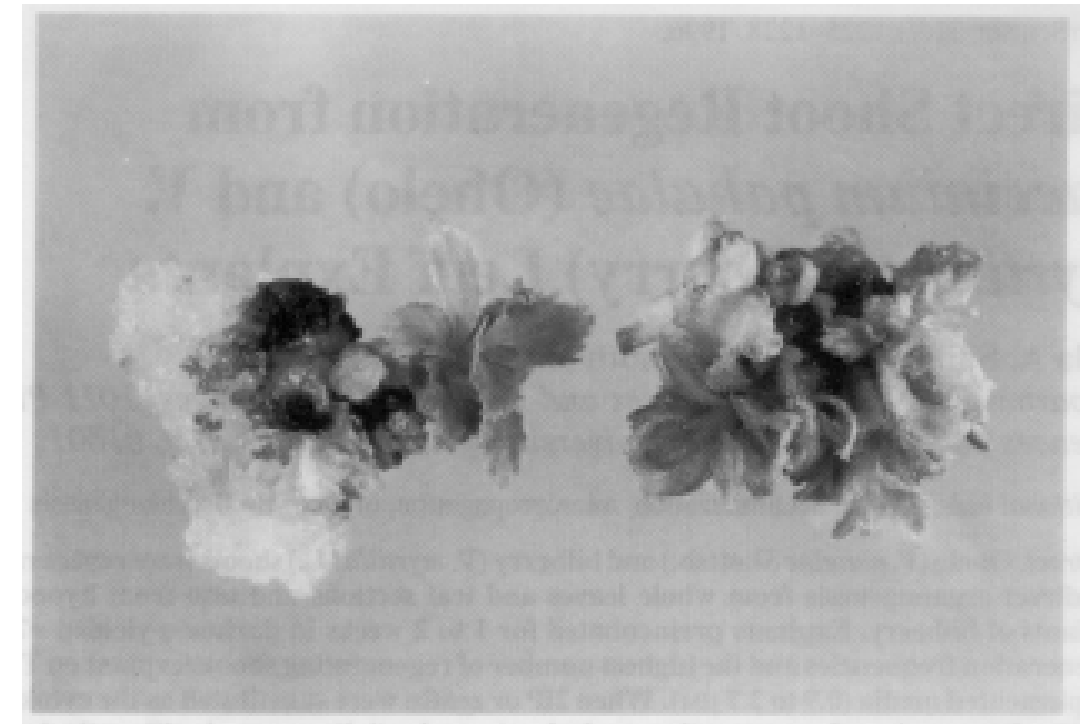

Fig. 1. Regeneration from whole leaves of ohelo, after 4 weeks incubation (including 2 weeks in darkness) in a regeneration medium containing at $2.7 \mu \mathrm{M}$ TDZ.
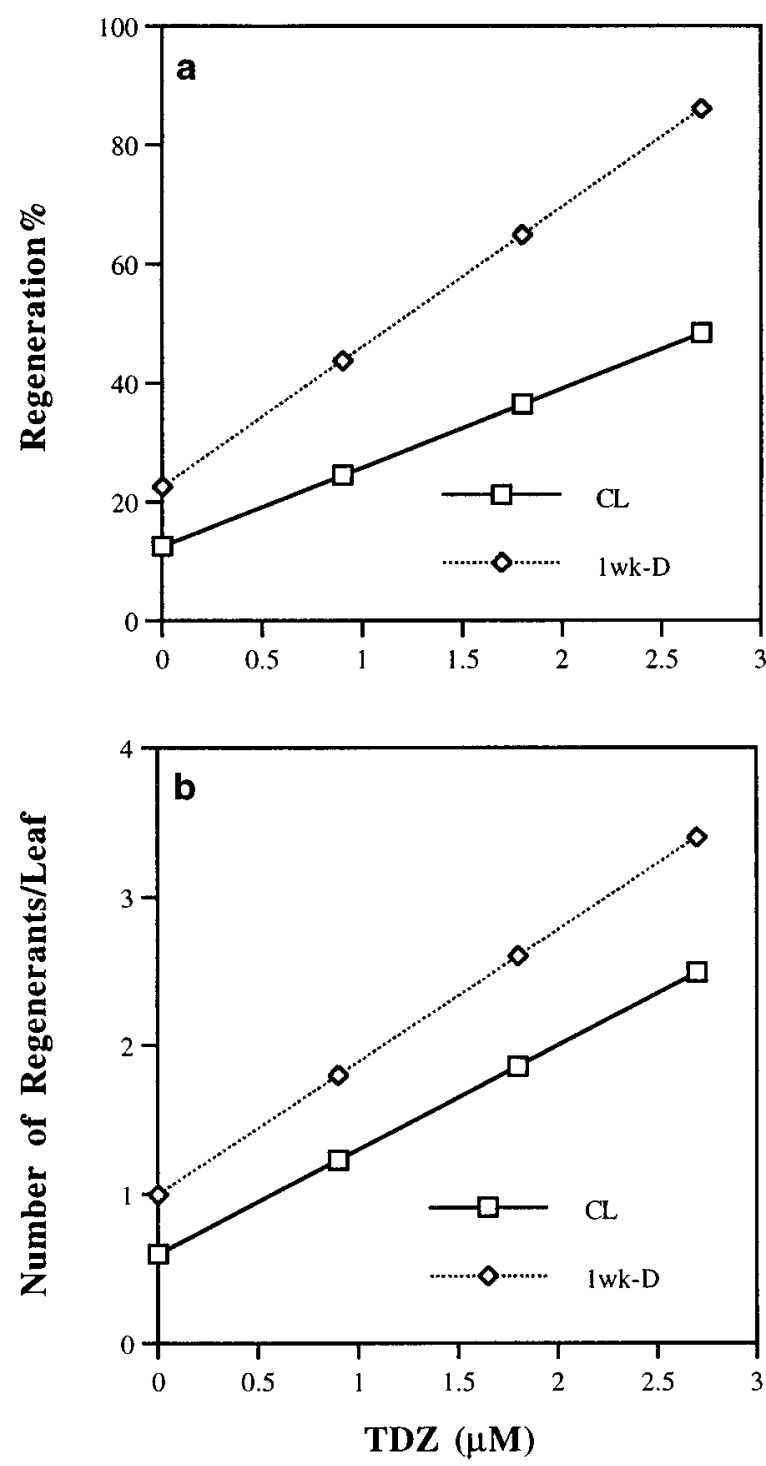

Fig. 2. Regeneration from whole leaves of ohelo on TDZ-supplemented medium. CL = explants held in continuous light; $1 \mathrm{wk}-\mathrm{D}=$ explants held 1 week in darkness prior to exposure to light. (a) Regeneration percentages. CL: $\mathrm{y}=12.5+13.3 \mathrm{x} ; r^{2}=0.69$. 1wk-D: $\mathrm{y}=22.6+23.5 \mathrm{x} ; r^{2}=0.69$. (b) Number of regenerated shoots per individual explant. CL: $\mathrm{y}=0.6+0.7 \mathrm{x} ; r^{2}=0.74$. $1 \mathrm{wk}-\mathrm{D}: \mathrm{y}=1.0+0.9 \mathrm{x} ; r^{2}=0.66$ 
emerging adventitious shoots. Although callus also formed on ohelo explants (Fig. 1), shoots emerged only from vegetative tissue, and no regeneration occurred from callus. TDZ-supplemented medium supported much higher percentages of regeneration from ohelo leaf explants (Fig. 2a) than either of the other cytokinins tested. Callus formation, but no regeneration, was induced by $2,4-\mathrm{D}$-supplemented media.

Both the percent regeneration and number of regenerated shoots arising from an individual leaf explant (Fig. 2b) were dramatically enhanced by pretreatment of explants in darkness before exposure to light in the growth room. With 0.9 and $1.8 \mu \mathrm{M} \mathrm{TDZ}$, for example, dark preincubation more than doubled the ohelo regeneration percentage compared to the same treatments incubated under continuous illumination. Similar enhancement of regeneration followed 1 - and 2-week dark preincubations; therefore, only the former set of treatments with TDZ is compared to culture of explants in continuous illumination (Fig. 2 $a$ and $b$ ). While dark pretreatment of explants also significantly improved regeneration performance for the kinetin or zeatin treatments (data not shown), even the least responsive (continuous light) treatment with TDZ outperformed all treatments with other cytokinins, in any light regime.

Parallel trends observed for bilberry explants (Fig. $3 \mathrm{a}$ and b) confirmed that TDZ evoked the best regeneration response from leaf explants, and that dark preincubation of leaves for 1 or 2 weeks consistently enhanced both regeneration percentage and number of regenerating shoots per explant. In contrast to ohelo, callus formation was minimal in bilberry. Regeneration percentages ranged between $15 \%$ and $30 \%$ higher with TDZ plus a dark pretreatment, as compared to the parallel treatments with other cytokinins.

Shoots began to appear on leaf surfaces after 1 week in the dark and after about 12 to 14 days under direct light in both genotypes (Figs. $2 \mathrm{a}$ and $\mathrm{b}$ and $3 \mathrm{a}$ and $\mathrm{b}$ ). After transfer to proliferation media, the shoots established proliferating cultures and did not show any phenotypic variation.

Half leaf sections showed a similar pattern of regeneration to that of whole leaves, except that the overall regeneration percentage was decreased and the number of regenerants was about one-third to one-half of that from whole leaves. Shoots regenerated from hypocotyls of germinating bilberry seeds after 2 weeks in dark storage. TDZ was also most effective in regeneration from half leaf or hypocotyl explants. Small interveinal leaf sections of bilberry and ohelo and the cotyledonary leaves of germinating bilberry seedlings regenerated on $1.8 \mu \mathrm{M}$ TDZ, $59.0 \mu \mathrm{M} 2 \mathrm{iP}$, and $27.4 \mu \mathrm{M}$ zeatin when incubated for 2 weeks in darkness (data not shown).

Although TDZ has supported regeneration in many plant species, to our knowledge, this is the first study to report the use of TDZ in regeneration from Vaccinium. While some organogenesis from vegetative tissues has been reported (Rowland and Ogden, 1992; Serres et
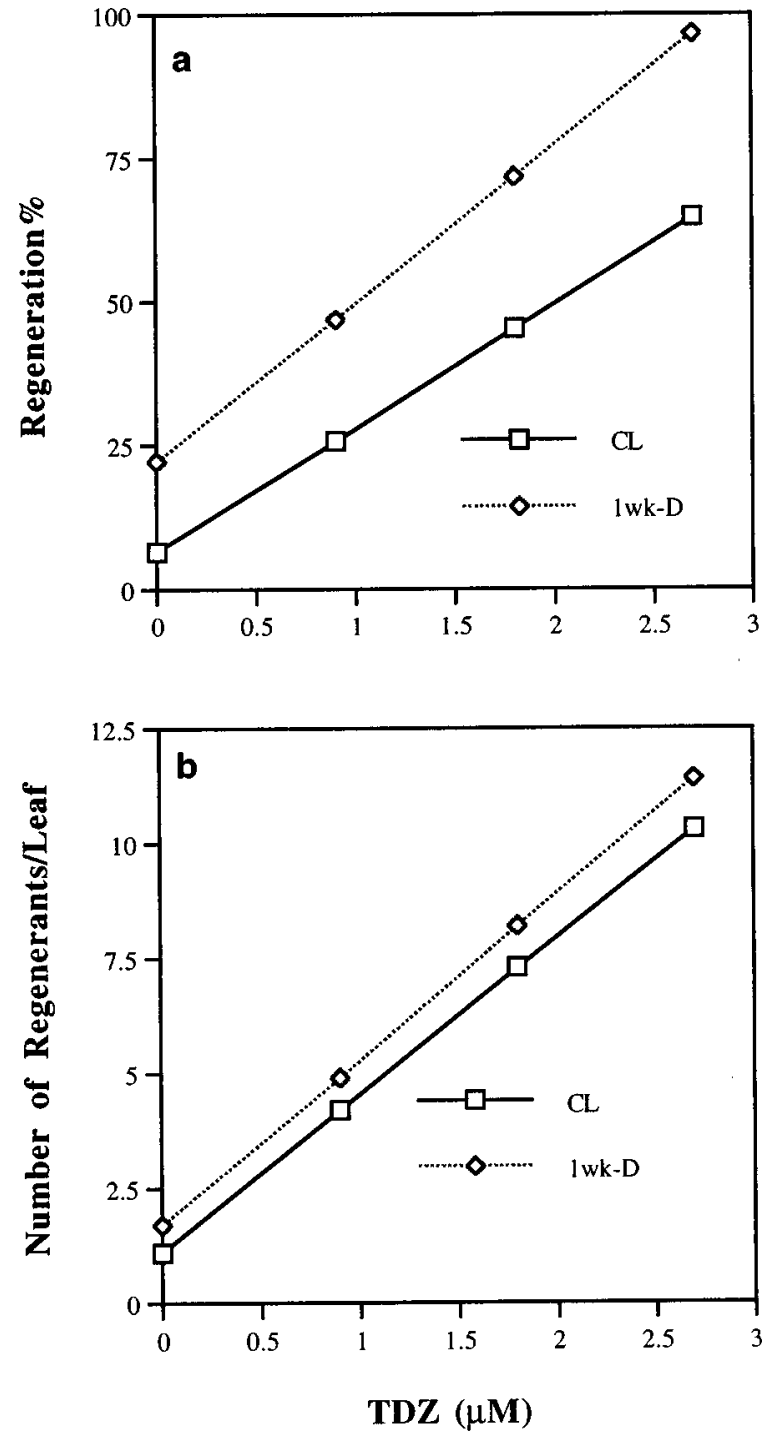

Fig. 3. Regeneration from whole leaves of bilberry on TDZ-supplemented medium. CL $=$ explants held in continuous light; $1 \mathrm{wk}-\mathrm{D}=$ explants held 1 week in darkness before exposure to light. (a) Regeneration percentages. CL: $\mathrm{y}=6.6+21.5 \mathrm{x} ; r^{2}=0.89 .1 \mathrm{wk}-\mathrm{D}: \mathrm{y}=22.1+27.6 \mathrm{x} ; r^{2}=0.77$. (b) Number of regenerated shoots per individual explant. CL: $\mathrm{y}=1.1+3.4 \mathrm{x} ; r^{2}=0.90$. $1 \mathrm{wk}-\mathrm{D}: \mathrm{y}=1.7+3.6 \mathrm{x} ; r^{2}=0.88$.

al., 1992), no reports have indicated successful organogenesis or embryogenesis from Vaccinium callus. Callus and suspension cultures demonstrated no potential for plantlet regeneration in these experiments, although callus maintained over 2 months without subculturing occasionally exhibited rhizogenesis.

In vitro shoot proliferation. $2 \mathrm{iP}$ and zeatin effectively supported shoot cultures of both species. Shoot count, FM, and DM each increased (Fig. 4), and shoot height was depressed, with increasing concentrations of cytokinin. Callus frequently formed at higher concentrations of $2 \mathrm{iP}$ or zeatin, but no shoots regenerated from callus. Zeatin generally supported more vegetative growth in ohelo than 2iP treatments (Fig. 4 b and d); however, zeatin-treated cultures produced hyperhydric tissue, and a plethora of very small shoots was generated. Hyperhydration was more pronounced in ohelo than in bilberry. For these reasons, shoots produced in $2 \mathrm{iP}$-supplemented media were far more amenable to subsequent rooting and acclimatization.
While $2 \mathrm{iP}$ and zeatin have been successfully used to support shoot proliferation for Vaccinium genotypes (Marcotrigiano and McGlew, 1991; Reed and Esquivel, 1991), zeatin is less economical for routine maintenance of micropropagated stock because of its high cost relative to $2 \mathrm{iP}$.

Rooting and acclimatization. Neither ohelo nor bilberry demonstrated any visible rooting response in any of the in vitro treatments with exogenous auxin, although $40 \%$ of bilberry shoots rooted in vitro (after 8 weeks) in the absence of growth regulators. The in vitrorooted bilberry microshoots were successfully acclimatized, with 95\% survival in the greenhouse. Insignificant in vitro rooting was reported previously for cranberry (Scorza et al., 1984) on medium containing 5.8 $\mu \mathrm{M}$ IAA, and blueberry rooted with a $40 \%$ frequency on medium containing $10.7 \mu \mathrm{M}$ NAA or without auxin (Zimmerman and Broome, 1979).

In an ex vitro environment, in contrast, microcuttings from both species rooted. Bilberry microcuttings rooted with an $85 \%$ fre- 

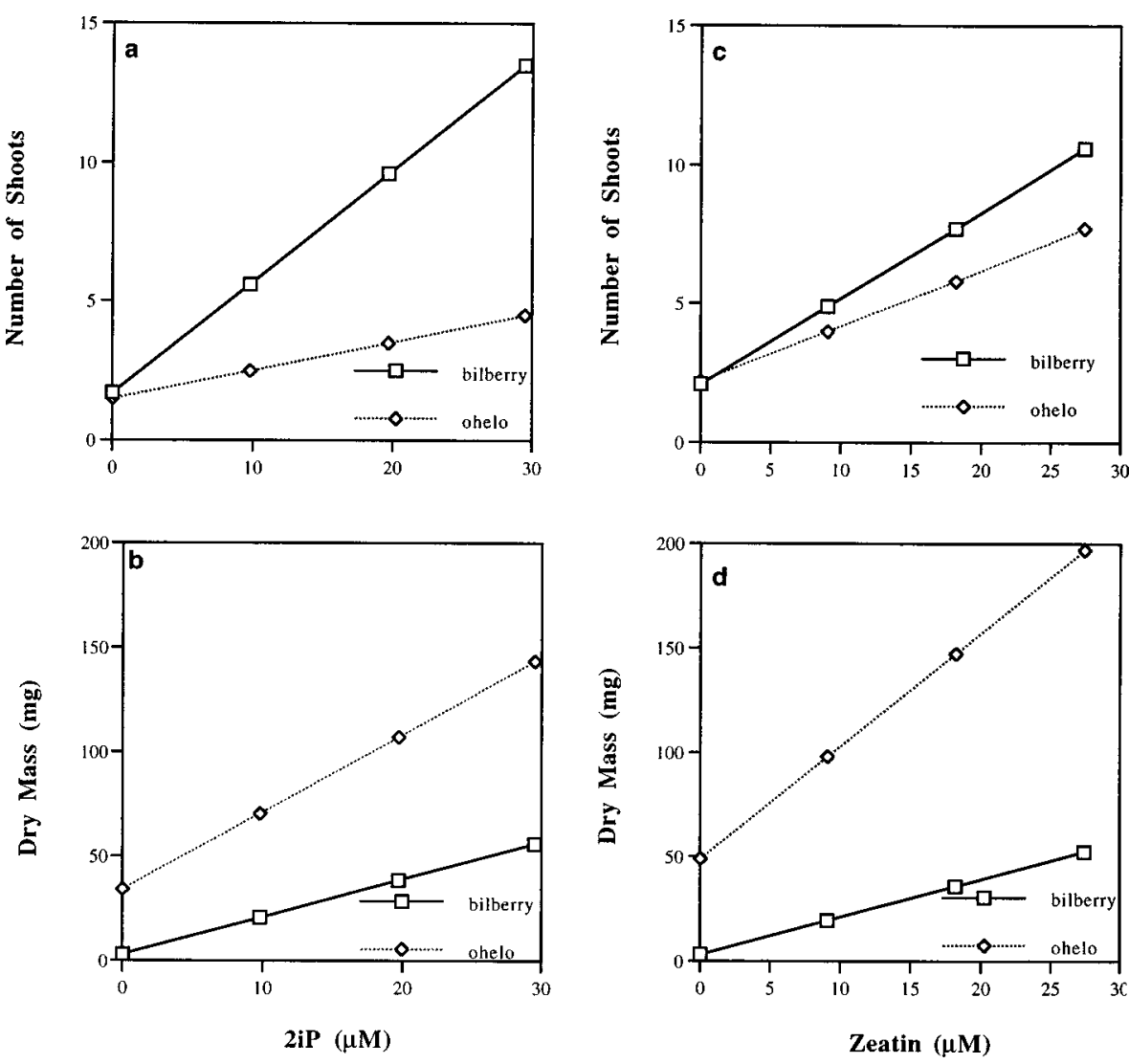

Fig. 4. Influence of $2 \mathrm{iP}$ and zeatin on shoot proliferation and growth of ohelo and bilberry. Data were collected after 8 weeks in each proliferation treatment; similar trends were observed after 4 weeks in vitro. (a) Shoot numbers in $2 \mathrm{iP}$-supplemented treatments. Ohelo: $\mathrm{y}=1.5+0.1 \mathrm{x} ; r^{2}=0.81$. Bilberry: $\mathrm{y}$ $=1.7+0.4 \mathrm{x} ; r^{2}=0.75$. (b) Dry mass of shoots in 2iP-supplemented treatments. Ohelo: $\mathrm{y}=34.1+3.7 \mathrm{x}$ $r^{2}=0.45$. Bilberry: $\mathrm{y}=3.0+1.8 \mathrm{x} ; r^{2}=0.75$. (c) Shoot numbers in zeatin-supplemented treatments. Ohelo: $\mathrm{y}=2.2+0.2 \mathrm{x} ; r^{2}=0.66$. Bilberry: $\mathrm{y}=2.1+0.3 \mathrm{x} ; r^{2}=0.84$. (d) Dry mass of shoots in zeatin-supplemented treatments. Ohelo: $\mathrm{y}=48.9+5.4 \mathrm{x} ; r^{2}=0.48$. Bilberry: $\mathrm{y}=3.1+1.8 \mathrm{x} ; r^{2}=0.68$.

quency when planted in soilless mixture (without growth regulator treatment) and maintained under acclimatization conditions. Treating the basal end by dipping for 2 to $3 \mathrm{~s}$ in a solution of $4.9 \mu \mathrm{M}$ of IBA or $5.4 \mu \mathrm{M}$ NAA increased the rooting percentage to $95 \%$ for bilberry and also encouraged a $60 \%$ rooting response for ohelo. Rooted microcuttings showed $95 \%$ (bilberry) and $70 \%$ (ohelo) survival during acclimatization under intermittent misting in the greenhouse. Acclimatized plants grew slowly in the greenhouse. Lower survival percentages for ohelo reflected a greater sensitivity to desiccation for this plant. Pretreatment of microcuttings with exogenous auxins in vitro, followed by ex vitro rooting, was of no advantage, because unrooted cuttings in medium with IBA or NAA rapidly became necrotic when transferred to ex vitro rooting and acclimatization conditions.

Ex vitro rooting (without auxin applica- tion) was previously reported for lingonberry microshoots in a peat-vermiculite medium in a high humidity chamber (Hosier et al., 1985). Blueberry and cranberry microcuttings also were reported to root under ex vitro conditions (Isutsa et al., 1994; Marcotrigiano and McGlew, 1991).

This study explored some procedures for rapid regeneration and micropropagation of two valuable Vaccinium genotypes. Media supplementation with TDZ (0.9 to $2.7 \mu \mathrm{M})$ coupled with a 1 to 2 week preincubation of explanted leaves in darkness resulted in the best organogenesis response from both species. While both cytokinins supported subsequent shoot proliferation of the regenerants, zeatin had the disadvantage of provoking hyperhydration. Ex vitro rooting of microshoots yielded plants that were readily acclimatized to the greenhouse. Regeneration and micropropagation from vegetative explants can be used for further research work in genetic transformation and breeding.

\section{Literature Cited}

Callow, P., K. Haghighi, M. Giroux, and J. Hancock. 1989. In vitro regeneration of leaf tissue from micropropagated highbush blueberry. HortScience 24:373-375.

Childs, 1995. Functional foods and market entry. World of Ingredients. Oct. 1995. p. 36.

Colatuoni, A., S. Betuglia, M.J. Magistretti, and L. Donato. 1991. Effects of Vaccinium myrtillus anthocyanosides on arterial vasomotion. Arznei Forsch. 41:905-909.

Finn, C.E., J.J. Luby, C.J. Rosen, and P. D. Ascher. 1991. Evaluation in vitro of blueberry germplasm for higher $\mathrm{pH}$ tolerance. J. Amer. Soc. Hort. Sci. 116:312-316.

Hosier, M.A., G.F. Flatebo, and P.E. Read. 1985. In vitro propagation of lingonberry. HortScience 20:364-365.

Isutsa, D. K., M.P. Pritts, and K.W. Mudge. 1994. Rapid propagation of blueberry plants using ex vitro rooting and controlled acclimatization of micropropagules. HortScience 29:1124-1126.

Lloyd, G. and B. McCown. 1980. Commerciallyfeasible micropropagation of mountain laurel Kalmia latifolia, by use of shoot-tip culture. Proc. Intl. Plant Prop. Soc. 30:421-427.

Madhavi, D.L., M.A.L. Smith, and R. Rogers. 1995. Expression of anthocyanins in bilberry and huckleberry callus cultures. In Vitro Cell. Devel. Biol. 31:66A. Abstr. P-1072.

Marcotrigiano M. and S.P. McGlew. 1991. A twostage micropropagation system for cranberries. J. Amer. Soc. Hort. Sci. 116:911-916.

Mohamed, M.F., P.E. Read, and D.P. Coyne. 1992. Plant regeneration from in vitro culture of embryonic axis explants in common and tepary beans. J. Amer. Soc. Hort. Sci. 117:332-336.

Morazzoni, P. and E. Bombardelli. 1996. Vaccinium myrtillus L. Fitoterapia 66:3-29.

Murashige, T. and F. Skoog. 1962. A revised medium for rapid growth and bioassays with tobacco tissue culture. Physiol. Plant. 15:473497.

Reed, B.M. and A.A. Esquivel. 1991. The use of zeatin to initiate in vitro cultures of Vaccinium species and cultivars. HortScience 26:13201322.

Rowland, L.J. and E.L. Ogden. 1992. Use of a cytokinin conjugate for efficient shoot regeneration from leaf sections of highbush blueberry. HortScience 27:1127-1129.

Scorza, R., W.V. Welker, and L.J. Dunn. 1984. The effect of glyphosate, auxin, and cytokinin combinations on in vitro development of cranberry node explants. HortScience 19:66-68.

Serres, R., E. Stang, D. McCabe, D. Russell, D. Mahr, and B. H. McCown. 1992. Gene transfer using electric discharge particle bombardment and recovery of transformed cranberry plants. J. Amer. Soc. Hort. Sci. 117:174-180.

Zimmerman, R.H. and O.C. Broome. 1979. Propagation of blueberries through tissue culture. HortScience 14:477-478. 